\title{
Journal of Cancer
}

Case Report

$2011 ; 2: 206-209$

\section{Primary Solitary Fibrous Tumor of the Thyroid - Report of a Case and Re- view of the Literature}

\author{
Zhigang Song ${ }^{1}$, Chunkai Yu² , Xin Song ${ }^{1}$, Lixin Wei ${ }^{1}$, Aijun Liu ${ }^{1 凶}$
}

1. Department of Pathology, the Chinese PLA General Hospital, Beijing, 100853, China

2. Department of Pathology, Peking Union Medical College Hospital, Chinese Academy of Medical Science \& Peking Union Medical College, Beijing, 100730, China

Corresponding author: Aijun Liu, MD, Department of Pathology, the Chinese PLA General Hospital, 28 Fuxing Rd, Beijing 100853, China. Email: liuaj@301hospital.com.cn; Telephone: +86-10-66936253

(c) Ivyspring International Publisher. This is an open-access article distributed under the terms of the Creative Commons License (http://creativecommons.org/ licenses/by-nc-nd/3.0/). Reproduction is permitted for personal, noncommercial use, provided that the article is in whole, unmodified, and properly cited.

Received: 2011.03.02; Accepted: 2011.04.11; Published: 2011.04.13

\begin{abstract}
Solitary fibrous tumor (SFT) is a rare spindle-cell neoplasm, especially in the thyroid. We report a case of primary solitary fibrous tumor of the thyroid gland in a 37 year-old Chinese man. The tumor was characterized by bland-looking spindle cells admixed with thin and thick collagen fibers. On immunohistochemistry study indicated that tumor cells were diffusely positive for CD34, Bcl-2 and CD99, and negative for Desmin, NSE, SMA, S-100, and CD68. The patient remains well 16 months after excision. The morphologic and immunohistochemical features of the thyroid SFTs are similar to their reported counterparts in other anatomic sites.
\end{abstract}

Key words: solitary fibrous tumor; thyroid

\section{Introduction}

A 37 year-old Chinese man presented to our hospital for evaluation of a painless left cervical mass in September 2009. At that time, he underwent a cervical ultrasound, which showed a thyroid mass with clear margin. The subtotal thyroidectomy was undergone in October 2009. Upon intraoperative exam, his surgeons noted a single well circumscribed tumor with $3 \mathrm{~cm}$ in diameter in the left lobe of the thyroid, while no abnormality with the right lobe and without lymphadenectasis of neck were found.

The pathologic specimen showed the tumor was an orbicular-ovate solid mass with hard texture and $4 \mathrm{~cm} \times 2.5 \mathrm{~cm} \times 2.5 \mathrm{~cm}$ in size. The cut surface was pale and firm, and had a whorled appearance (Fig.1). Microscopically, the tumor was composed of spindle cells with a mixture of hypocellular (collagenous) and hypercellular area. The spindle cells arranged in var- ious patterns, including storiform, wavy, desmoidlike, palisading and hemangiopericytoma-like (Fig. 2). In hypercellular areas, the cells were spindle or orbicular-ovate with finely dispersed chromatin and inconspicuous and small nucleoli. In hypocellular areas, the cells were elongated to spindle lacking nucleoli. No cytological atypia, necrosis, and hemorrhage were found. In the margin of the tumor, the entrapped follicles can be seen (Fig.2). In some area, follicular cells had squamous metaplasia and acidophilia metaplasia. The mitotic figures were rare $[<1$ /10 high-power field (HPF)]. Immunohistochemically, tumor cells were strongly positive for CD99, Bcl-2 and CD34, but negative for Desmin, Neurone-specific enolase (NSE), Smooth muscle actin (SMA), S-100, or CD68. Ki-67 index is lower than 5\% (Fig. 3). Entrapped follicles were positive for thyroid globin (TG). 
The final pathological diagnosis is thyroid gland solitary fibrous tumor of the left lobe.

\section{Discussion}

Solitary fibrous tumor (SFT) is a rare spindle-cell neoplasm, which was first reported by Klemperer and Rabin in 1931 as a pleural tumor [1]. Subsequently, it has been recognized in other organs of the body [2-13]. Furthermore, distinct immunohistochemical features and electron microscopy findings supported a fibroblastic differentiation of the tumor. Therefore, it is now widely accepted that SFT is a quite ubiquitous neoplasm of likely mesenchymal origin.

SFT arising in the thyroid is very rare. Since Taccagni et al. first reported in 1993, only 23 cases have been reported in the literature [2-14]. It often occurs in adults, with an average age of 49.5 years (range from 28 to 76 years old). Among 24 cases, including the present one, 15 cases were male and the other 9 cases were female [Table 1]. Thyroid SFT has no pathognomonic clinical feature and presents with a painless slowly increasing mass. The patient reported with the intrathoracic tumor had increasing respiratory symptoms that were thought to be caused by his well-known asthma. The etiopathogenisis of SFT is not clear, but in some cases occurred in the thyroid presented with a background of long-standing goiter $[1,12,14]$, however, the herein reported case showed no goiter and found by phsycal examination.

Most thyroid SFTs appeared as large well-circumscribed solid lesions, with whitish to grayish color on cut surface. The tumor was circumscribed with or without encapsulation. Microscopically, the lesions were characterized by a proliferation of spindle cells arranged in various patterns, includ- ing storiform, wavy, desmoid-like, palisading, and hemangiopericytic. Immunohistochemically, tumor cells were strongly positive for vimentin, CD34, CD99, and BCL-2[1]. All these above features are similar to its counterparts occurred in the pleura and other sites.

There were no distinct pathologic criteria that may definitely differentiate benign from malignant variants of SFT. In the reported 23 cases of thyroid SFT, only one case had recurrence and pulmonary metastasis. The herein case showed no evidence of recurrence 16 months after operation. The features that suggest aggressive behavior include high cellularity, moderate to marked cytological atypia, higher frequency of mitoses ( $>4 / 10 \mathrm{HPFs})$, evidence of tumor necrosis, and infiltrating margins [14]. So, long-term follow-up should be recommended especially to the cases with aggressive features.

The differential diagnosis of SFT of the thyroid gland includes Riedel thyroiditis, fibrosing Hashimoto's thyroiditis, leiomyoma, peripheral nerve origin tumors and undifferentiated carcinoma. Riedel thyroiditis and fibrosing Hashimoto's thyroiditis are diffuse fibrous mass with marked infiltrating lymphocytes, wheras the SFT of thyroid is well-circumscribed mass without notable lymphocytes. For leiomyoma and peripheral nerve origin tumors, immunohistochemical staining are specific positive for SMA and S-100, repectively, while nagetive for CD34 and Bcl-2. Undifferentiated carcinoma is charecterized by highly pleomorphic tumor cells that lack any organoid growth pattern. A component of papillary carcinoma, follicular carcinoma or poor differentiated thyroid carcinoma often can be found and express the epithelial markers.

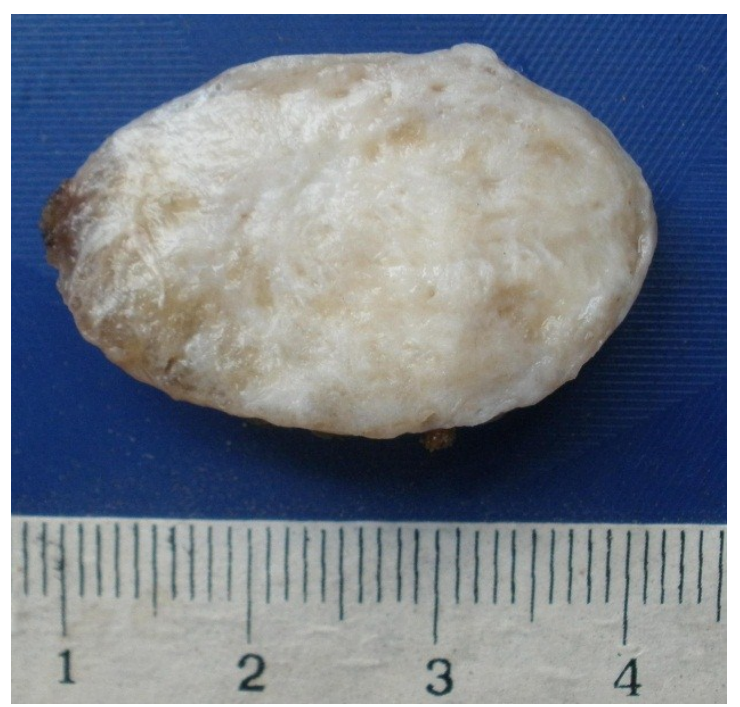

Fig. I Gross specimen of the SFT of the thyroid. A solid, well-circumscribed, white nodule with whitish cut surface. 

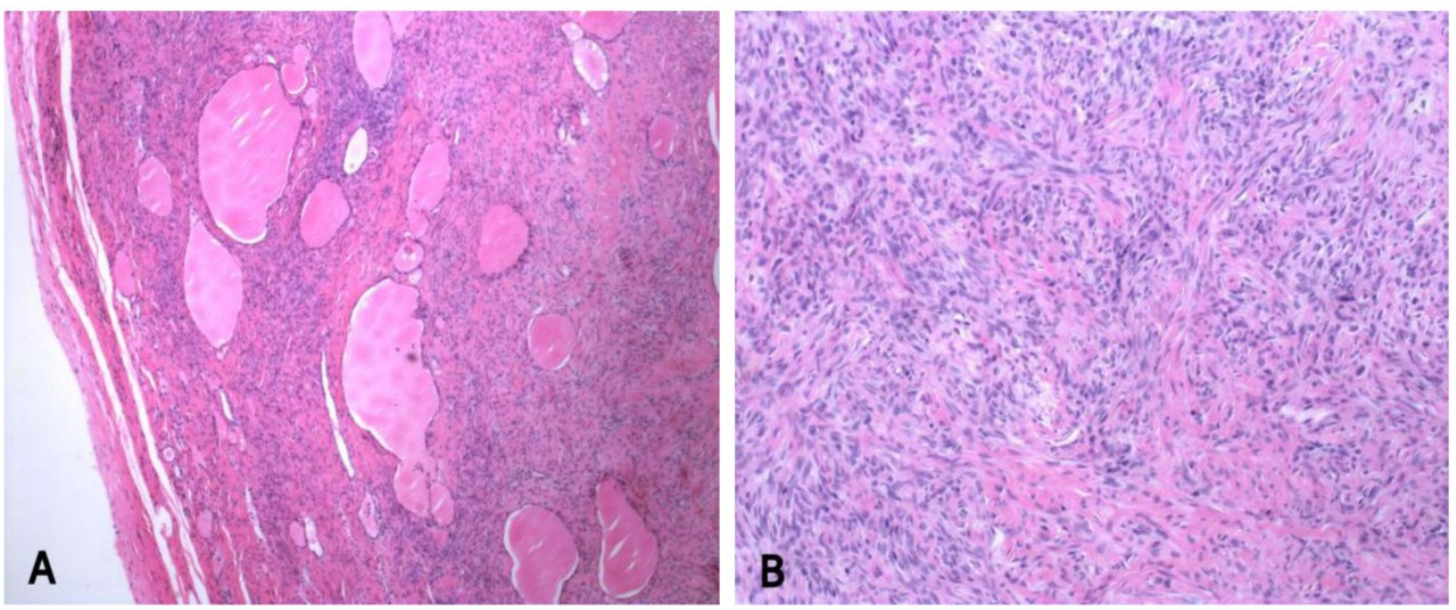

Fig. 2 Histological examination of the SFT of the thyroid. 2A: The capsule of thyroid is not involved, while the entrapped follicles can be seen.(H\&E staining, original magnification 40x), 2B: The tumor cells are abundant with whorled arrangement. (H\&E staining, original magnification 100x)
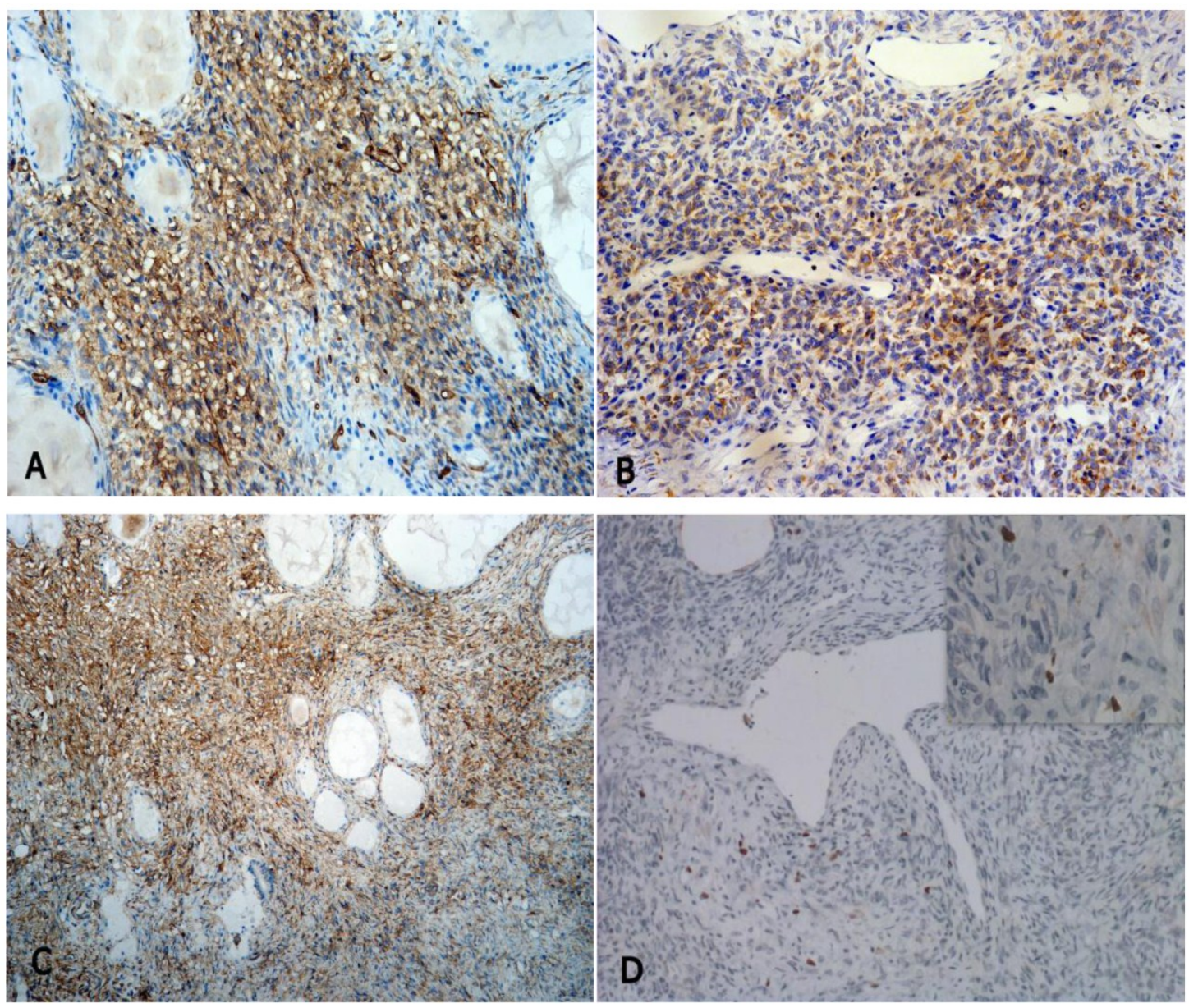

Fig. 3 The immunohistochemical staining of the SFT of the thyroid (EnVision method), showing positive for CD34 (A, original magnification I00x), bcl-2 (B, original magnification I00x), CD99 (C, original magnification 40x), and lower Ki-67 index (D, original magnificaion $100 x$, the up-right inserted picture 400x), respectively. 
Table I Reported cases of thyroid solitary fibrous tumor

\begin{tabular}{|c|c|c|c|c|c|c|}
\hline Case & Gender & Age & Size $(\mathrm{cm})$ & Site & Follow up (month) & Reference \\
\hline 1 & $\mathrm{~F}$ & 44 & 6.5 & $\mathrm{R}$ & NED, 60 & [2] \\
\hline 2 & $\mathrm{M}$ & 61 & 6 & $\mathrm{~L}$ & NED, 48 & [2] \\
\hline 3 & $\mathrm{~F}$ & 32 & 3.5 & $\mathrm{R}$ & NED, 60 & [2] \\
\hline 4 & M & 43 & 4 & NA & NED, 160 & [3] \\
\hline 5 & $\mathrm{~F}$ & 48 & 8 & $\mathrm{R}$ & NA & [4] \\
\hline 6 & $\mathrm{~F}$ & 28 & 2.5 & NA & LTF & [5] \\
\hline 7 & $\mathrm{~F}$ & 43 & 3.5 & $\mathrm{~L}$ & LTF & [6] \\
\hline 8 & M & 52 & 2.5 & $\mathrm{~L}$ & LTF & [6] \\
\hline 9 & $\mathrm{M}$ & 44 & 2 & $\mathrm{~L}$ & LTF & [6] \\
\hline 10 & $\mathrm{~F}$ & 64 & 4.5 & $\mathrm{R}$ & NED, 60 & [6] \\
\hline 11 & M & 53 & 6 & $\mathrm{~L}$ & NED, 60 & [6] \\
\hline 12 & $\mathrm{~F}$ & 47 & 4.5 & $\mathrm{R}$ & NED, 48 & [6] \\
\hline 13 & $\mathrm{~F}$ & 64 & 3 & $\mathrm{~L}$ & NA & [6] \\
\hline 14 & $\mathrm{M}$ & 56 & 8 & $\mathrm{R}$ & NED, 12 & [7] \\
\hline 15 & $\mathrm{M}$ & 68 & 9.7 & $\mathrm{~L}$ & NED, 54 & [8] \\
\hline 16 & $\mathrm{M}$ & 45 & 5 & $\mathrm{~L}$ & NA & [9] \\
\hline 17 & $\mathrm{M}$ & 64 & 5 & $\mathrm{R}$ & NED, 57 & [10] \\
\hline 18 & $\mathrm{M}$ & 41 & 3 & $\mathrm{R}$ & NED, 45 & [10] \\
\hline 19 & $\mathrm{M}$ & 64 & 5 & $\mathrm{R}$ & NED, 60 & [11] \\
\hline 20 & $\mathrm{M}$ & 41 & 3 & $\mathrm{R}$ & NED, 48 & [11] \\
\hline 21 & $\mathrm{M}$ & 51 & NR & $\mathrm{L}$ & NA & [12] \\
\hline 22 & $\mathrm{~F}$ & 76 & NA & $\mathrm{R}$ & Rec, MT,6 & [13] \\
\hline 23 & $\mathrm{M}$ & 58 & 8 & Intrathoracic & NA & [14] \\
\hline Current case & M & 37 & 3 & $\mathrm{~L}$ & NED, 12 & \\
\hline
\end{tabular}

L, left lobe; R, right lobe; LTF, lost to follow up; NED, no evidence of disease, NA, not available; Rec, recurrence; MT, metastasis.

\section{Conflict of Interest}

The authors have declared that no conflict of interest exists.

\section{References}

1. Taccagni G, Sambade C, Nesland J, et al. Solitary fibrous tumor of the thyroid: Clinicopathological,immunohistochemical and ultrastructural study of three cases. Virchows Arch A Pathol Anat Histopathol. 1993;422(6):491-7.

2. Cameselle-Teijeiro J, Varela-Duran J, Fonseca E, et al. Solitary fibrous tumor of the thyroid. Am J Clin Pathol. 1994; 101:535-538

3. Kie J, Kim J, Park Y. Solitary fibrous tumor of the thyroid. Histopathology. 1997;30:365-368.

4. Brunnemann R, Ro J, Ordonez N, et al. Extrapleural solitary fibrous tumor: A clinicopathologic study of 24 cases. Mod Pathol 1999;12(11):1034-42.

5. Rodriguez I, Ayala E, Caballero C, et al. Solitary fibrous tumor of the thyroid gland: report of seven cases. Am J Surg Pathol. 2001; 25:1424-1428

6. Deshmukh N, Mangham D, Warfield A, et al. Solitary fibrous tumor of the thyroid gland. J Laryngol Otol 2001;115(11):940-942.

7. Bohorquez CL, Gonzalez-Campora R, Loscertales MC, et al. Solitary fibrous tumor of the thyroid with capsular invasion. Pathol Res Pract. 2003; 199:687-690
8. Babouk NL. Solitary fibrous tumor of the thyroid gland. Saudi Med J. 2004; 25:805-807

9. Tanahashi J, Kashima K, Daa T, et al. Solitary fibrous tumor of the thyroid gland: report of two cases and review of the literature. Pathol Int. 2006; 56:471-477

10. Santeusanio G, Schiaroli S, Ortenzi A, et al. Solitary fibrous tumour of thyroid: report of two cases with immunohistochemical features and literature review. Head Neck Pathol. 2008; 2:231-235

11. Farrag TY, Micchelli S, Tufano RP. Solitary fibrous tumor of the thyroid gland. Laryngoscope. 2009; 119:2306-2308

12. Ning S, Song X, Xiang L, et al. Malignant solitary fibrous tumor of the thyroid gland: Report of a case and review of the literature. Diagn Cytopathol. 2010; [Epub ahead of print]

13. Larsen SR, Godballe C, Krogdahl A. Solitary fibrous tumor arising in an intrathoracic goiter. Thyroid. 2010; 20:435-437

14. Papi G, Corrado S, Uberti ED, et al. Solitary fibrous tumor of the thyroid gland. Thyroid. 2007; 17:119-126 